\title{
Effect of Low Protein-High Calory or Essential Fatty Acid Deficiency Diet on Reproduction of Rainbow Trout
}

\author{
Takeshi Watanabe, ${ }^{* 1}$ Toshio Takeuchi, ${ }^{* 1}$ Minoru Sarto, ${ }^{* 2}$ \\ and Kazuhisa NISHIMURA*2
}

(Accepted June 21, 1983)

\begin{abstract}
A feeding experiment was conducted to investigate effects of quality of diets, given to rainbow trout broodstock for 3 months before their spawning, on the reproduction and egg quality by feeding various diets, with different levels of protein and lipid or a diet without supplemental essential fatty acid (EFA).

The growth rate and feed efficiency were high in the broodstock receiving the diet containing $36 \%$ protein and $18 \%$ lipid and in addition eyed rate and total hatch were also high in the eggs produced by the broodstock of this group. The growth and feed efficiency in the fish kept on the diet containing $28 \%$ protein became slow from around 60 days after feeding. Feeding the diet containing beef tallow as a part of energy source gave good results with regard to reproduction, comparable to those obtained in the broodstock fed on a commercial high protein diet. The EFA-deficient diet was found to result in low growth rates, eyed eggs and hatchability, and these results were also found to be effectively improved by supplementing ethyl linoleate to the diet, indicating importance of EFA for reproduction.

The results of this study have demonstrated that egg quality was greatly affected by the nutritional quality of diets given to rainbow trout broodstock for a short-period of 3 months before their spawning.
\end{abstract}

In the previous experiment ${ }^{13}$ in which fingerlings of rainbow trout were fed on various diets for 3 years, it was demonstrated that the low proteinhigh calory diets supplemented with beef tallow had no adverse effects on reproduction of rainbow trout, and that a supplement of trace elements to fish meal diets is indispensable for reproduction, although white fish meal contained various kinds of minerals. Among various kinds of possible factors which affect gonadal maturation and spawning, quality of feed was found to be closely related to reproduction of rainbow trout and red sea bream $\mathrm{m}^{2) * 3}$ in the former experiments. However, the effect of the duration of the period over which diets are fed which may affect gonadal maturation remains unknown. This study was conducted to investigate effects of quality of diets given to fish for 3 months before spawning on the reproduction of rainbow trout. For this purpose rainbow trout broodstock were given various diets with different levels of protein and lipids or a diet without supplement of essential fatty acids (EFA). The results obtained have demonstrated that the reproduction and egg quality were deeply affected by the nutritional quality of diets given to broodstock for 3 months before spawning.

\section{Materials and Methods}

\section{Feeding of Rainbow Trout Broodstock}

Eggs produced from the rainbow trout broodstock maintained at the Okutama Branch of the Tokyo Metropolitan Fisheries Experimental Station were hatched and the larvae were fed on a commercial rainbow trout diet for 1.5 years, growing up to about $600 \mathrm{~g}$ in body weight. Twelve to fourteen adult female and one to three male broodstock were then selected and stocked in each of concrete tanks $(3.5 \times 1.5 \times 0.3 \mathrm{~m})$ in the station. The rearing water used was a mixture of underground and river water (temperature range $6-20^{\circ} \mathrm{C}$ ). The broodstock were given the

*1 Laboratory of Fish Nutrition, Tokyo University of Fisheries, Konan 4, Minato, Tokyo 108, Japan (渡辺 武・竹内俊郎: 東京水産大学水族栄堒学講座).

*2 The Okutama Branch of Tokyo Metropolitan Fisheries Experimental Station, Kotaba, Okutama, Tokyo 198-01, Japan（齐藤 実・西村和久: 東京都水産訆験埸)。

*3 T. Kitajima, A. Itoh, T. Kitada, T. Ohta, T. Watanabe, and S. Fujta: Oral presentation at the annual meeting of Japan. Soc. Sci. Fish., in Mie, November, 1981. 
Table 1. Compositions of the experimental diets

\begin{tabular}{|c|c|c|c|c|c|c|c|}
\hline \multirow{2}{*}{ Ingredient } & \multicolumn{7}{|c|}{ Diet no. } \\
\hline & 1 & 2 & 3 & 4 & 5 & 6 & 7 \\
\hline Fish meal & 48 & 64 & 80 & 63 & - & - & \\
\hline Casein & - & - & - & - & 44 & 44 & \\
\hline Wheat flour & 20 & 10 & 0 & 2 & 6 & 6 & \\
\hline$\alpha-$ Starch & 16 & 16 & 16 & 16 & 16 & 16 & \\
\hline Cellulose & 12 & 6 & 0 & 5 & 7 & 7 & Commercial \\
\hline $\mathrm{CMC}$ & - & - & - & 1 & 1 & 1 & $\operatorname{diet}(5 \mathrm{P})$ \\
\hline Vitamin mix. & 2 & 2 & 2 & 2 & 2 & 2 & \\
\hline Mineral mix. & 2 & 2 & 2 & 4 & 4 & 4 & \\
\hline Beef tallow & - & - & - & 7 & - & - & \\
\hline Methyl laurate & - & - & - & - & 5 & 5 & \\
\hline Total & 100 & 100 & 100 & 100 & 85 & 85 & 100 \\
\hline Feed oil & 20 & 14 & 9 & 7 & - & - & 5 \\
\hline Methyl laurate & - & - & - & - & 10 & 5 & - \\
\hline Ethyl linoleate & - & - & - & - & - & 5 & - \\
\hline Crude protein & 28.2 & 36.3 & 45.7 & 40.1 & 42.9 & 42.9 & 43.1 \\
\hline Crude lipid & 20.8 & 17.5 & 14.6 & 19.4 & 14.0 & 14.0 & 12.7 \\
\hline
\end{tabular}

experimental diets shown in Table 1 for 3 months, from August to November, and did not then feed for about 1 month because of low temperature before spawning in January. Each test diet was given twice daily.

Table 1 shows the composition of the experimental diets. Diets 1 to 3 were processed into porous pellets, containing white fish meal at levels of 48,64 , and $80 \%$, respectively. In diet 4 containing $63 \%$ white fish meal, $7 \%$ of beef tallow was added in order to examine the availability of lipid as an energy source for rainbow trout..,4) Diets 5 and 6 containing casein as a protein source were used to examine the effect of EFA deficiency on the reproduction of rainbow trout. Diets 5 contained $15 \%$ methyl laurate as a sole lipid source, and $10 \%$ of methyl laurate in the diet was substituted by the same amount of ethyl linoleate in Diet 6. The broodstock which continued to feed on the commerical diet in another pond of the station were used as the control (diet 7). Diets 4 to 6 were processed into ordinary pellets by using California Laboratory Pellet Mill (Model CL-2). A commercial feed oil (pollock liver oil) was added to diets 1, 2, 3, 4 and 7 at levels shown in Table 1 just before the administration to fish. Methyl laurate was added to diets 5 and 6 , together with ethyl linoleate to diet 6 in the same way. The purities of methyl laurate purchased from the Tokyo Chemical Industry Co. Ltd. and of ethyl linoleate from the Kanto Chemical Industry Co. Ltd., were found to be 99 and $98 \%$, respectively when checked by gas-liquid chromatography.

In January six female rainbow trout broodstock were selected from each experimental lot for spawning. Male broodstock were obtained from the group which had been rearing for mass propagation at the station. Eggs were fertilized by the washing method. ${ }^{(5)}$

Other experimental conditions, such as analytical procedure, preparation of diets, fish care, and feeding, were all described earlier. ${ }^{8-8)}$

\section{Results and Discussion}

\section{Results of Feeding}

Results of the feeding are summarized in Table 2 and Fig. 1. In the group of broodstock fed on the diets containing white fish meal as a protein source, it is noticeable that the growth rate and feed efficiency in broodstock receiving diet 2 containing $36 \%$ protein and $18 \%$ lipid were com-

Table 2. Results of 3 months of feeding from August 18 to November 19

\begin{tabular}{|c|c|c|c|c|c|}
\hline \multirow{2}{*}{$\begin{array}{c}\text { Diet } \\
\text { no. }\end{array}$} & \multirow{2}{*}{$\begin{array}{c}\text { Number } \\
\text { of } \\
\text { fish }\end{array}$} & \multicolumn{2}{|c|}{ Av, body wt (g) } & \multirow{2}{*}{$\begin{array}{l}\text { Percent } \\
\text { gain }\end{array}$} & \multirow{2}{*}{$\begin{array}{l}\text { Feed ef } \\
\text { ficiency } \\
(\%)\end{array}$} \\
\hline & & Initial & Final & & \\
\hline 1 & 15 & 623 & 945 & 51.7 & 50.5 \\
\hline 2 & 15 & 593 & 1017 & 71.5 & 73.8 \\
\hline 3 & 15 & 660 & 1143 & 73.2 & 83.2 \\
\hline 4 & 15 & 639 & 1000 & 56.5 & 61.9 \\
\hline 5 & 15 & 580 & 756 & 30.3 & 48.9 \\
\hline 6 & 15 & 597 & 823 & 37.9 & 67.4 \\
\hline
\end{tabular}




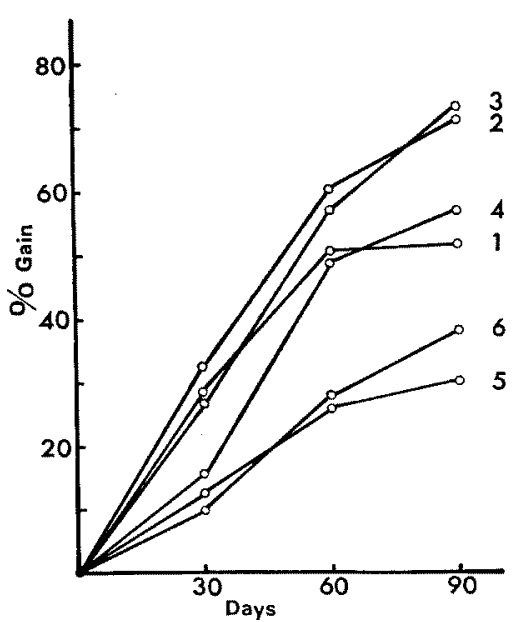

Fig. 1. Results of the feeding experiment with rainbow trout broodstock. Curves 1 to 3 , fish fed the diets containing white fish meal at levels of 48,64 and $80 \%$, respectively. Curve 4 , fish fed the diet containing $63 \%$ white fish meal and $7 \%$ beef tallow as an energy source. Curves 5 and 6 , fish fed the casein diet containing $15 \%$ methyl laurate as a sole lipid source or $10 \%$ methyl laurate plus $5 \%$ ethyl linoleate, respectively.

parable to those in fish receiving diet 3 containing $46 \%$ protein and $15 \%$ lipid. While in the fish fed on the $28 \%$ protein diet with a high level of lipid (diet 1) the growth rate together with feed efficiency was gradually declining from about 60 days after feeding. Feeding the diet containing beef tallow as a contributory energy source (diet 4) resulted in slow growth until about 30 days after feeding because the trout took longer than did other groups to accustom to the diet, but the growth rate gradually recovered to a level comparable to that of fish receiving diet 2. As already reported in the previous paper, ${ }^{11}$ it has been demonstrated that the low-protein diet with a high energy content enriched with beef tallow gave good results for reproduction in rainbow trout, comparable to those obtained in the broodstock fed on a commercial high protein diet. On the other hand, the casein diets containing lauric acid (diets 5 and 6 ) were disliked by brookstock, resulting in much lower feeding rates than in the other groups receiving white fish meal diets. Consequently the growth rates in these groups were significantly lower, although the feed efficiency was improved by addition of ethyl linoleate. The rate of EFA-deficiency broodstock became slow from around 60 th day after feeding.

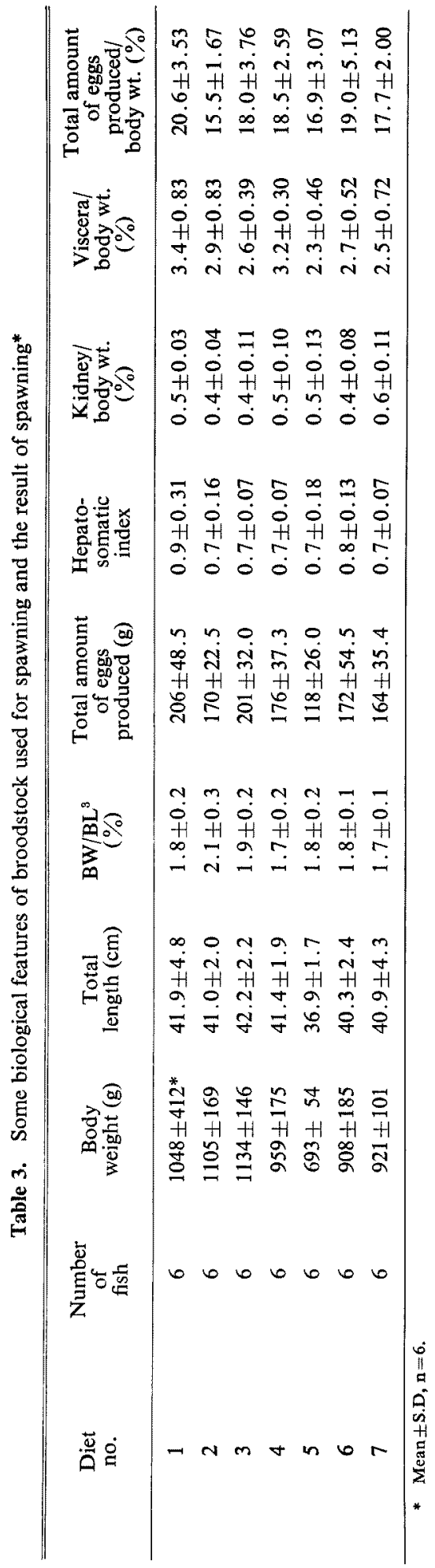


Some Biological Features of Broodstock Used for Spawning

Each of six female broodstock from each experimental lot was used for spawning. Some biological features of broodstock such as body weight, body length, condition factor and hepatosomatic index are summarized in Table 3. These were no marked differences in body weight, hepatosomatic index, the percentage of kidney and viscera to body weight among broodstock from each experimental lot except for the fish receiving the EFA-deficient diet (diet 5), although the fish body weights of the groups fed on diets 1,2 and 3 were slightly larger than those of the other groups and the rate of eggs produced to body weight was highest in the group of diet 1 , lowest in the group of diet 2. In fingerling rainbow trout, feeding an EFA-deficient diet usually results in swollen pale liver accompanying fatty degeneration, ${ }^{\theta, 10)}$ however in the case of broodstock in this experiment this phenomenon was not recognized. As shown in Fig. 2, the total amount of eggs produced was found to increase exponentially in proportion to body length, as reported by NomURA. ${ }^{11}$

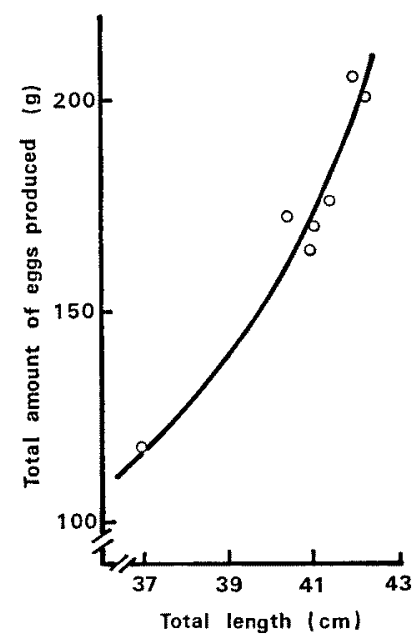

Fig. 2. Exponential relationship between the total body length of female broodstock and the total amount of eggs produced.

\section{Results of Spawning}

The total amount of eggs produced per one female broodstock, egg diameter, percentage of eyed eggs and their rate of hatching, all indicated by average value of eggs from six females, are summarized in Table 4. Sperm used for fertiliza-
Table 4. Results of measurement on egg quality

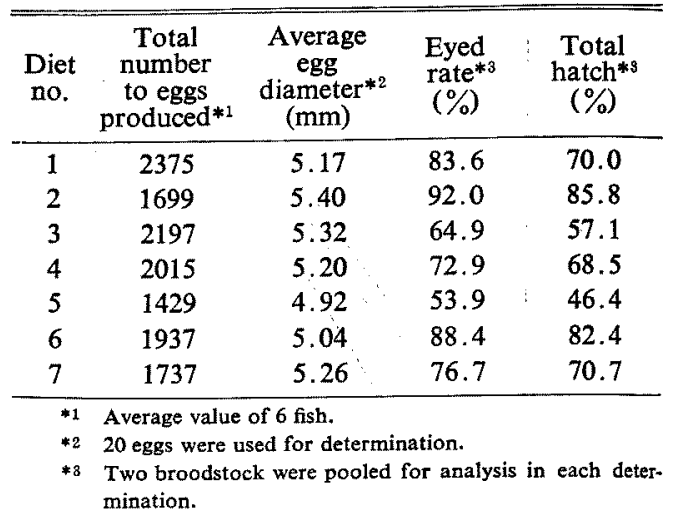

tion was all obtained from male broodstock which had been kept on the same commercial diet as diet 7 of the control group in a pond of mass propagation at the station.

In this experiment measurement of egg quality was conducted by using eggs produced by the broodstock of the first spawning, resulting in generally low values in each determination. In addition, each value fluctuated significantly among broodstock of the same group because it was the first spawning. The total number of eggs produced by any one group of broodstock was highest in the fish fed on the low-protein diet, and lowest in the fish receiving the EFA-deficient diet. In the latter group the size of eggs was also lowest. The percentage of eyed eggs was not so markedly different due to difference of diets ranging from $65-90 \%$ when compared with that of $77 \%$ in the control group, except for the EFA-deficient group, although the highest value of $92 \%$ was obtained in the group receiving diet 2 . In the eggs from EFA-deficient broodstock not only was the percentage of eyed eggs lowest, but also the rate of total hatch in the experimental groups, indicating that total fry obtained from all the eggs produced was only $25 \%$. Thus the growth rate as well as the egg quality was found to be greatly affected by nutritional deficiency of diets, as found previously in both rainbow trout ${ }^{1)}$ and red sea bream. ${ }^{2)}$

Addition of beef tallow to the diet (diet 4) as an energy source had no adverse effect on the reproduction on rainbow trout, and this coincides well with the results of the previous experiment1) in which quality of eggs was determined on those obtained from the 2 nd spawning, giving high values of $85-90 \%$ in both the rates of eyed eggs and total hatch, after 3 years feeding with the same 
diet as diet 4. An EFA-deficient diet was also reported to result in low hatchability in the case of chicken and hen. ${ }^{12,13)}$

On the other hand, addition of linolenic acid (18: $3 \omega 3)$ as a sole fatty acid source was reported to satisfy the EFA requirement of rainbow trout broodstock for their reproduction, ${ }^{14)}$ and also the EFA value of $18: 2 \omega 6$ is well known to be much inferior to $18: 3 \omega 3$ for rainbow trout fingerlings, ${ }^{15,10)}$ quite different from the case of broodstock in this experiment where the percentage of fertilization, eyed eggs and total hatch was effectively improved by supplementation of ethyl linoleate to the EFA-deficient diet to a level comparable to that of pollock liver oil (diets 1-4 and 7).

Proximate Composition of Whole Body of Broodstock, Eggs and Sperm

Average values of 3 female broodstock are shown in Table 5. Unlike fingerlings feeding the EFAdeficient diet did not result in swollen pale liver with increased level of neutral lipid in the broodstock, although the moisture content increased and the lipid level decreased in the muscle. This suggests a difference of EFA-deficiency between broodistock and fingerlings. However, the latter phenomenon in the EFA-deficient muscle may be due to an effect of starvation for about 2 months before spawning, because starvation of carp which had been fed an EFA-deficient diet resulted in an increase of water content and a decrease of lipid level in the whole bodies. ${ }^{17)}$ The lipid content of viscera was greatly affected by dietary lipid levels, and was proportional to lipid levels in diets. ${ }^{18,19)}$ The lowest value was obtained in the broodstock fed on the diet containing lauric acid as a sole lipid source (diet 5), and was improved approximately to the same level as that in the control receiving a commercial diet (diet 7) by the addition of ethyl linoleate. The proportion of polar to nonpolar lipids in liver tissue was not affected by dietary lipids, and was almost constant among the experimental groups. ${ }^{10,20)}$

As shown in Table 6, there was no marked difference in the values of proximate analyses for eggs obtained from each group of broodstock, they were not affected by the composition of diet unlike other tissues, although the lipid content of sperm ranged from 0.5 to $1.3 \%$, being lowest in the group fed on the EFA-deficient diet.

\section{Fatty Acid Distribution in Liver Polar Lipid}

As shown in Table 7, there was no marked difference in the fatty acid composition of liver polar lipid fractions from broodstock fed diets

Table 5. Proximate compositions of the experimental broodstock*

\begin{tabular}{|c|c|c|c|c|c|c|c|}
\hline \multirow{2}{*}{$\begin{array}{l}\text { Diet } \\
\text { no. }\end{array}$} & \multicolumn{3}{|c|}{ Muscle } & \multirow{2}{*}{$\begin{array}{l}\text { Viscera } \\
\text { Lipid }\end{array}$} & \multirow{2}{*}{$\begin{array}{l}\text { Liver } \\
\text { Lipid }\end{array}$} & \multicolumn{2}{|c|}{$\%$ in Liver } \\
\hline & Moisture & Protein & Lipid & & & Polar & Nonpolar \\
\hline 1 & $78.2 \pm 1.7$ & $19.1 \pm 0.4$ & $3.3 \pm 0.6$ & $31.0 \pm 7.1$ & $4.1 \pm 0.3$ & - & \\
\hline 2 & $76.5 \pm 0.7$ & $19.2 \pm 0.4$ & $3.5 \pm 0.4$ & $26.0 \pm 3.2$ & $4.2 \pm 0.2$ & 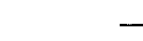 & \\
\hline 3 & $77.2 \pm 0.3$ & $19.2 \pm 1.1$ & $3.4 \pm 1.0$ & $19.5 \pm 6.3$ & $4.5 \pm 0.5$ & $\ldots$ & \\
\hline 4 & $77.7 \pm 1.0$ & $18.8 \pm 0.2$ & $3.3 \pm 0.6$ & $12.8 \pm 3.2$ & $4.0 \pm 0.2$ & $2.9 \pm 0.1$ & $1.1 \pm 0.1$ \\
\hline 5 & $78.6 \pm 1.0$ & $18.4 \pm 0.7$ & $2.3 \pm 0.1$ & $5.6 \pm 2.0$ & $3.9 \pm 0.3$ & $2.7 \pm 0.2$ & $1.0 \pm 0.1$ \\
\hline 6 & $77.3 \pm 0.9$ & $19.6 \pm 0.3$ & $3.0 \pm 0.9$ & $15.5 \pm 7.4$ & $4.1 \pm 0.2$ & $2.9 \pm 0.1$ & $1.3 \pm 0.2$ \\
\hline 7 & $77.0 \pm 0.5$ & $19.5 \pm 0.8$ & $3.1 \pm 0.6$ & $17.7 \pm 5.3$ & $4.1 \pm 0.5$ & $2.8 \pm 0.2$ & $1.3 \pm 0.4$ \\
\hline
\end{tabular}

- Mean $\pm S D, n=3$ (Two broodstock were pooled for analysis in each determination)

Table 6. Proximate compositions of the eggs and sperm*

\begin{tabular}{|c|c|c|c|c|c|c|}
\hline \multirow{2}{*}{$\begin{array}{l}\text { Diet } \\
\text { no. }\end{array}$} & \multicolumn{3}{|c|}{ Egg } & \multicolumn{2}{|c|}{$\%$ in Egg } & \multirow{2}{*}{$\begin{array}{l}\text { Sperm } \\
\text { Lipid }\end{array}$} \\
\hline & Moisture & Protein & Lipid & Polar & Nonpolar & \\
\hline 1 & $59.6 \pm 0.6$ & $28.9 \pm 1.7$ & $10.8 \pm 0.6$ & - & - & 1.2 \\
\hline 2 & $59.6 \pm 0.2$ & $29.1 \pm 0.4$ & $10.5 \pm 0.3$ & - & - & 0.8 \\
\hline 3 & $59.1 \pm 1.2$ & $29.3 \pm 0.5$ & $10.7 \pm 0.2$ & - & - & 0.7 \\
\hline 4 & $59.9 \pm 0.7$ & $28.7 \pm 0.4$ & $11.3 \pm 0.1$ & $4.7 \pm 0.2$ & $6.6 \pm 0.1$ & 0.8 \\
\hline 5 & $60.0 \pm 0.7$ & $28.6 \pm 0.4$ & $10.2 \pm 0.2$ & $4.5 \pm 0.1$ & $5.7 \pm 0.3$ & 0.5 \\
\hline 6 & $61.3 \pm 1.0$ & $27.8 \pm 0.3$ & $10.1 \pm 0.7$ & $4.3 \pm 0.2$ & $5.9 \pm 0.6$ & 0.7 \\
\hline 7 & $60.2 \pm 0.7$ & $28.1 \pm 0.4$ & $11.0 \pm 0.4$ & $4.5 \pm 0.2$ & $6.5 \pm 0.3$ & 1.3 \\
\hline
\end{tabular}

\footnotetext{
* See the footnote of Table 5 .
} 
Table 7. Fatty acid compositions of polar lipid fractions from the livers (area $\%)^{*}$

\begin{tabular}{|c|c|c|c|c|}
\hline \multirow{2}{*}{$\begin{array}{c}\text { Fatty } \\
\text { acid }\end{array}$} & \multicolumn{4}{|c|}{ Diet no. } \\
\hline & 4 & 5 & 6 & 7 \\
\hline $12: 0$ & - & - & $\operatorname{tr}$ & - \\
\hline $14: 0$ & $0.7 \pm 0.07$ & $1.2 \pm 0.35$ & $1.3 \pm 0.16$ & $0.6 \pm 0.16$ \\
\hline $16: 0$ & $18.8 \pm 2.20$ & $18.1 \pm 2.00$ & $18.6 \pm 0.43$ & $19.7 \pm 0.06$ \\
\hline $16: 1$ & $2.3 \pm 0.04$ & $2.3 \pm 0.33$ & $2.0 \pm 0.28$ & $1.8 \pm 0.46$ \\
\hline $18: 0$ & $10.8 \pm 0.84$ & $9.8 \pm 0.43$ & $10.9 \pm 1.36$ & $10.1 \pm 0.08$ \\
\hline $18: 1$ & $16.1 \pm 0.67$ & $16.6 \pm 0.94$ & $13.9 \pm 2.34$ & $12.8 \pm 0.14$ \\
\hline $18: 2 \omega 6$ & $4.6 \pm 0.28$ & $6.0 \pm 0.15$ & $8.6 \pm 1.23$ & $6.3 \pm 0.55$ \\
\hline $18: 3 \omega 3$ & $0.3 \pm 0.03$ & $0.2 \pm 0.02$ & $0.2 \pm 0.07$ & $0.2 \pm 0.08$ \\
\hline $20: 1$ & $1.3 \pm 0.20$ & $1.8 \pm 1.06$ & $1.3 \pm 0.19$ & $1.2 \pm 0.15$ \\
\hline $20: 2 \omega 6$ & $0.5 \pm 0.05$ & $1.1 \pm 0.22$ & $1.9 \pm 0.20$ & $1.1 \pm 0.06$ \\
\hline $20: 3 \omega 9$ & - & - & - & - \\
\hline $20: 3 \omega 6$ & $0.8 \pm 0.09$ & $1.9 \pm 0.42$ & $2.3 \pm 0.32$ & $1.8 \pm 0.82$ \\
\hline $20: 4 \omega 6$ & $4.9 \pm 0.06$ & $6.0 \pm 0.70$ & $10.0 \pm 0.28$ & $6.6 \pm 0.60$ \\
\hline $20: 4 \omega 3$ & $0.3 \pm 0.04$ & $0.2 \pm 0.05$ & $0.2 \pm 0.10$ & $0.3 \pm 0.05$ \\
\hline $20: 5 \omega 3$ & $8.5 \pm 0.57$ & $5.6 \pm 1.01$ & $4.1 \pm 1.10$ & $5.7 \pm 0.24$ \\
\hline $22: 5 \omega 3$ & $2.4 \pm 0.08$ & $1.7 \pm 0.40$ & $1.3 \pm 0.48$ & $1.9 \pm 0.10$ \\
\hline $22: 6 \omega 3$ & $26.7 \pm 0.91$ & $26.8 \pm 2.80$ & $21.3 \pm 6.74$ & $29.7 \pm 0.54$ \\
\hline$\sum \omega 6$ & $10.9 \pm 0.43$ & $15.2 \pm 1.29$ & $24.2 \pm 1.89$ & $15.8 \pm 0.30$ \\
\hline$\Sigma \omega 3$ & $38.3 \pm 1.59$ & $34.4 \pm 3.09$ & $27.2 \pm 6.06$ & $37.8 \pm 0.57$ \\
\hline
\end{tabular}

* See the footnote of Table 5 .

containing beef tallow (diet 4) and lauric acid alone (diet 5) or the commercial diet (diet 7). Feeding the EFA-deficient diet resulted in no increased level of abnormal polyenoic acid "20:3 $3 \omega 9$ ", usually recognized in fingerling raunbow trout fed on a diet deficient in EFA. In the liver of broodstock which received ethyl linoleate (diet 6) the level of $18: 2 \omega 6$ and $20: 4 \omega 6$ increased, and that of $22: 6 \omega 3$ decreased, as affected by ethyl linoleate in the diet.

\section{Fatty Acid Distribution in Lipid of Eggs and Sperm}

Fatty acid distribution of polar lipid and triglyceride (TG) fractions from unfertilized eggs just after spawning is shown in Table 8 . When compared with the control group, the percentage of $\mathrm{C}_{18}$ and $\mathrm{C}_{18}$ monoenoic fatty acids increased and that of 22: $6 \omega 3$ decreased in both the fractions from the EFA-deficient group. In both fractions from eggs from the group given ethyl linoleate a similar result was obtained to that in liver that the level of 18:2 266 and 20: $4 \omega 6$ increased and that of 22:6w3 decreased. The result obtained in broodstock which had been kept on a commerical diet at the Nikko Branch of National Research Institute of Aquaculture is also given in Table 8, showing almost the same fatty acid distribution as that in the control broodstock in this experi- ment. Thus the fatty acid distribution in lipids of eggs was affected by lipids of diets for broodstock, as reported by LASKER and THEILACKER ${ }^{21}$ and ANDo. ${ }^{22)}$

Fatty acids of total lipids from sperm are shown in Table 9. The distribution of fatty acids in sperm was also found to be greatly affected by dietary fatty acids in the same manner as in the livers and eggs. However, the percentage of 20: $5 \omega 3$ was characteristically high in the former, and furthermore an increased level of $20: 3 \omega 9$ was recognized in the lipid of sperm from the EFA-deficient group, quite different from the latter tissues. A further experiment should be conducted to clarify whether the difference in fatty acid distribution in sperm lipids is responsible for activity of spermatozoa and rate of fertilization or eyed eggs.

The results of this study have demonstrated that egg quality is greatly affected by nutritional quality of diets given to broodstock rainbow trout for a short-period of 3 months before their spawning in the same manner as red sea bream. ${ }^{2)}$ Similar results to those reported previously ${ }^{12}$ showed that eggs produced from the fish fed on the low-protein diet with high energy value gave good yields of eyed eggs with high hatchability compared to those fed on the control commercial diet, and that supplement of beef tallow as a part of energy source 
Table 8. Fatty acid compositions of polar lipid and triglyceride(TG) fractions from the eggs (area \%)

\begin{tabular}{|c|c|c|c|c|c|c|c|c|c|c|}
\hline \multirow{3}{*}{ Fatty acid } & \multicolumn{8}{|c|}{ Diet no. } & & \\
\hline & \multicolumn{2}{|c|}{4} & \multicolumn{2}{|c|}{5} & \multicolumn{2}{|c|}{6} & \multicolumn{2}{|l|}{7} & \multicolumn{2}{|c|}{ Nikko } \\
\hline & Polar & TG & Polar & TG & Polar & TG & Polar & TG & Polar & TG \\
\hline $12: 0$ & - & $1.0 \pm 0.31 * 1$ & $1.0 \pm 0.43$ & $12.1 \pm 1.99$ & $1.0 \pm 0.18$ & $7.5 \pm 1.91$ & - & - & - & - \\
\hline $14: 0$ & $1.7 \pm 0.20$ & $3.3 \pm 0.19$ & $3.2 \pm 0.85$ & $7.9 \pm 0.78$ & $2.8 \pm 0.40$ & $6.2 \pm 0.56$ & $1.1 \pm 0.06$ & $2.3 \pm 0.05$ & $1.9 \pm 0.32 * 2$ & $4.5 \pm 0.54^{* 2}$ \\
\hline $16: 0$ & $20.1 \pm 2.73$ & $18.9 \pm 3.55$ & $16.3 \pm 1.60$ & $12.4 \pm 0.43$ & $15.8 \pm 1.11$ & $13.1 \pm 0.66$ & $20.1 \pm 1.31$ & $14.4 \pm 0.33$ & $20.0 \pm 0.71$ & $15.7 \pm 0.74$ \\
\hline $16: 1$ & $3.3 \pm 0.27$ & $9.8 \pm 1.25$ & $4.7 \pm 0.63$ & $10.7 \pm 0.71$ & $3.4 \pm 0.48$ & $9.2 \pm 0.88$ & $2.6 \pm 0.29$ & $9.3 \pm 1.26$ & $4.1 \pm 0.83$ & $12.9 \pm 0.97$ \\
\hline $18: 0$ & $10.3 \pm 0.47$ & $3.7 \pm 0.92$ & $10.2 \pm 0.69$ & $2.6 \pm 0.22$ & $11.7 \pm 1.24$ & $3.1 \pm 0.46$ & $9.8 \pm 0.40$ & $3.5 \pm 0.73$ & $11.9 \pm 0.44$ & $2.7 \pm 0.32$ \\
\hline $18: 1$ & $15.7 \pm 0.95$ & $33.2 \pm 2.23$ & $18.9 \pm 0.79$ & $32.9 \pm 0.35$ & $15.4 \pm 1.52$ & $29.1 \pm 1.26$ & $13.2 \pm 0.20$ & $31.3 \pm 0.67$ & $17.0 \pm 0.36$ & $33.0 \pm 1.46$ \\
\hline $18: 2 \omega 6$ & $2.2 \pm 0.71$ & $3.4 \pm 0.93$ & $5.2 \pm 0.16$ & $5.0 \pm 0.43$ & $6.5 \pm 0.96$ & $12.0 \pm 1.07$ & $5.2 \pm 0.20$ & $13.2 \pm 0.22$ & $1.9 \pm 0.37$ & $4.0 \pm 0.25$ \\
\hline $18: 3 \omega 3$ & $0.2 \pm 0.04$ & $0.6 \pm 0.34$ & $0.3 \pm 0.05$ & $0.3 \pm 0.04$ & - & $0.3 \pm 0.12$ & $0.5 \pm 0.06$ & $0.8 \pm 0.10$ & $\operatorname{tr}$ & $0.4 \pm 0.06$ \\
\hline $20: 1$ & $2.9 \pm 0.07$ & $3.7 \pm 0.24$ & $3.1 \pm 0.15$ & $2.4 \pm 0.04$ & $2.6 \pm 0.32$ & $2.6 \pm 0.48$ & $2.7 \pm 0.26$ & $3.0 \pm 0.13$ & $4.1 \pm 0.29$ & $4.6 \pm 0.19$ \\
\hline $20: 2 \omega 6$ & $0.8 \pm 0.38$ & $0.4 \pm 0.09$ & $2.7 \pm 0.40$ & $0.9 \pm 0.11$ & $3.8 \pm 0.72$ & $2.4 \pm 0.31$ & $1.9 \pm 0.17$ & $1.3 \pm 0.06$ & $0.7 \pm 0.20$ & $0.5 \pm 0.11$ \\
\hline $20: 3 \omega 6$ & $1.3 \pm 0.49$ & $0.4 \pm 0.11$ & $4.0 \pm 0.51$ & $1.2 \pm 0.10$ & $4.8 \pm 1.41$ & $2.4 \pm 0.37$ & $3.4 \pm 0.91$ & $1.6 \pm 0.38$ & $0.8 \pm 0.13$ & $0.3 \pm 0.04$ \\
\hline $20: 4 \omega 6$ & $1.9 \pm 0.37$ & $0.5 \pm 0.17$ & $3.1 \pm 0.16$ & $0.7 \pm 0.11$ & $7.1 \pm 0.64$ & $2.2 \pm 0.61$ & $3.3 \pm 0.24$ & $1.1 \pm 0.18$ & $1.4 \pm 0.19$ & $0.5 \pm 0.10$ \\
\hline $20: 4 \omega 3$ & $0.4 \pm 0.09$ & $0.6 \pm 0.17$ & $0.2 \pm 0.05$ & $0.2 \pm 0.02$ & - & $\operatorname{tr}$ & $0.4 \pm 0.23$ & $0.4 \pm 0.08$ & $\operatorname{tr}$ & $0.5 \pm 0.29$ \\
\hline $20: 5 \omega 3$ & $7.1 \pm 0.83$ & $4.0 \pm 0.86$ & $2.7 \pm 0.30$ & $0.9 \pm 0.02$ & $1.8 \pm 1.04$ & & $4.2 \pm 0.23$ & & $6.6 \pm 0.56$ & $4.4 \pm 0.36$ \\
\hline $22: 1$ & $\operatorname{tr}$ & $\operatorname{tr}$ & - & $0.3 \pm 0.02$ & - & $1.0 \pm 0.23$ & $\operatorname{tr}$ & $2.7 \pm 0.31$ & - & - \\
\hline $22: 5 \omega 3$ & $2.5 \pm 0.07$ & $1.5 \pm 0.11$ & $1.5 \pm 0.16$ & $0.6 \pm 0.04$ & $1.1 \pm 0.47$ & $0.5 \pm 0.11$ & $1.9 \pm 0.09$ & $1.2 \pm 0.16$ & $2.0 \pm 0.26$ & $1.3 \pm 0.22$ \\
\hline $22: 6 \omega 3$ & $27.2 \pm 1.67$ & $11.4 \pm 1.74$ & $20.7 \pm 1.77$ & $6.3 \pm 0.41$ & $15.9 \pm 4.24$ & $4.4 \pm 1.41$ & $27.6 \pm 0.48$ & $11.0 \pm 0.48$ & $27.2 \pm 0.48$ & $12.2 \pm 1.96$ \\
\hline$\Sigma \omega 6$ & $6.8 \pm 2.60$ & $5.0 \pm 0.98$ & $16.8 \pm 0.11$ & $8.3 \pm 0.37$ & $27.7 \pm 2.94$ & $21.6 \pm 2.00$ & $14.6 \pm 0.60$ & $18.3 \pm 0.29$ & $4.8 \pm 0.66$ & $5.4 \pm 0.41$ \\
\hline$\Sigma \omega 3$ & $37.6 \pm 2.44$ & $18.2 \pm 2.38$ & $24.5 \pm 1.76$ & $8.4 \pm 0.44$ & $18.9 \pm 5.78$ & $6.3 \pm 1.58$ & $34.5 \pm 0.39$ & $16.1 \pm 0.55$ & $35.9 \pm 0.26$ & $19.1 \pm 1.84$ \\
\hline
\end{tabular}

*1 See the footnote of Table 5 .

*2 Mean $\pm S D, n=5$ (Quoted from the previous $p^{2}{ }^{24}$ )). 
Table 9. Fatty acid compositions of the total lipid from the sperm (area \%)

\begin{tabular}{lrrrrrrr}
\hline \hline \multirow{7}{*}{$\begin{array}{c}\text { Fatty } \\
\text { acid }\end{array}$} & \multicolumn{7}{c}{ Diet no. } \\
\cline { 2 - 8 } 1 & \multicolumn{1}{c}{2} & \multicolumn{1}{c}{3} & \multicolumn{1}{c}{4} & \multicolumn{1}{c}{5} & \multicolumn{1}{c}{6} & \multicolumn{1}{c}{} \\
\hline $14: 0$ & 0.9 & 2.4 & 1.7 & 1.5 & 3.2 & 3.2 & 1.0 \\
$16: 0$ & 17.5 & 27.6 & 29.1 & 24.0 & 21.9 & 22.2 & 23.9 \\
$16: 1$ & 4.6 & 2.6 & 2.6 & 2.6 & 4.7 & 2.1 & 2.1 \\
$18: 0$ & 4.4 & 5.1 & 6.5 & 5.7 & 5.2 & 5.0 & 4.7 \\
$18: 1$ & 14.9 & 16.8 & 20.7 & 17.7 & 25.3 & 13.0 & 15.0 \\
$18: 2 \omega 6$ & 5.3 & 3.3 & 1.8 & 2.3 & 3.4 & 10.1 & 5.9 \\
$18: 3 \omega 3$ & 0.7 & - & - & 0.3 & - & - & - \\
$20: 1$ & 0.9 & 2.2 & 2.2 & 1.4 & 1.6 & 0.5 & 0.9 \\
$20: 2 \omega 6$ & 0.5 & 0.4 & 0.3 & 0.3 & 0.7 & 1.7 & 0.9 \\
$20: 3 \omega 9$ & - & - & - & - & 2.0 & 0.9 & - \\
$20: 3 \omega 6$ & 0.5 & 0.1 & 0.6 & 0.4 & 2.0 & 2.9 & 1.0 \\
$20: 4 \omega 6$ & 3.7 & 2.1 & 2.9 & 4.0 & 3.6 & 12.2 & 3.9 \\
$20: 4 \omega 3$ & 0.8 & 0.4 & 0.4 & 0.4 & - & - & 0.5 \\
$20: 5 \omega 3$ & 17.9 & 16.7 & 14.2 & 16.2 & 5.5 & 4.8 & 11.1 \\
$22: 1$ & 0.4 & - & - & - & - & - & - \\
$22: 5 \omega 6$ & - & - & - & 1.3 & 1.4 & 6.9 & 1.0 \\
$22: 5 \omega 3$ & 1.7 & 1.9 & 2.0 & 2.1 & 1.5 & 1.1 & 1.5 \\
$22: 6 \omega 3$ & 21.5 & 17.8 & 15.0 & 19.2 & 18.1 & 12.2 & 26.4 \\
\hline$\Sigma \omega 6$ & 9.9 & 6.0 & 5.7 & 8.7 & 11.1 & 33.8 & 12.8 \\
$\Sigma \omega 3$ & 44.4 & 37.4 & 31.5 & 38.5 & 25.1 & 18.1 & 39.5 \\
\hline
\end{tabular}

had no adverse effects on reproduction of rainbow trout.

The EFA-deficient diet was found to result in a low rate of eyed egg production and of hatchability, indicating an importance of EFA for reproduction. SHmMa et al. ${ }^{29)}$ reported a relationship between hatchability and the proportion of 22: $6 \omega 3$ in the lipids of eggs from carp. The eggs with a low content of 22: $6 \omega 3$ from the EFAdeficient broodstock gave also a low rate of fertilization and hatchability, however, the eggs from the broodstock receiving ethyl linoleate (diet 6) were also low in the percentage of 22: $6 \omega 3$ but their egg quality was not different from those in the control group. This suggests that the importance of 22:6 63 in egg quality is not unique but may possibly be replaced by $20: 4 \omega 6$. The result also showed that $18: 2 \omega 6$ is also effective in reproduction of rainbow trout, although the EFA value of this fatty acid is well known to be inferior to $18: 3 \omega 3$ and $\omega 3$ highly unsaturated fatty acids. ${ }^{16,16)}$ Recently YU et al. ${ }^{14)}$ demonstrated by a long-term feeding that normal growth and reproduction of rainbow trout was obtained by

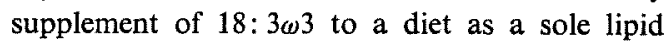
source. A further study will be necessary to clarify a relationship between EFA and reproduction by using broodstock of 2 nd spawning.

\section{Acknowledgements}

We express here out sincere thanks to Dr. C. B. CoweY, N.E.R.C. Institute of Marine Biochemistry, Aberdeen, Scotland, who kindly read the manuscript and gave valuable suggestions.

This study was supported in part by a Grant-inAid for Scientific Research of the Ministry of Education, Science and Culture.

\section{References}

1) T. TAkeuchi, T. Watanabe, C. Ogino, M. Saito, K. Nishimura, and T. Nose: Bull. Japan. Soc. Sci. Fish., 47, 645-654 (1981).

2) T. Watanabe, T. Arakawa, C. Kitajima, and $S$. Funta: Bull. Japan. Soc. Sci. Fish., 50, 495-501 (1984).

3) T. Takeuchi, T. Watanabe, and C. Ogino: Bull. Japan. Soc. Sci. Fish., 44, 875-881 (1978).

4) T. TAKEUCHI and T. WATANABE: Bull. Japan. Soc. Sci. Fish., 45, 1521-1525 (1979).

5) D. InABA, M. Nomura, and T. TominaGa: Bull. Japan. Soc. Sci. Fish., 23, 758-761 (1958).

6) J. C. Sipos and R. G. Ackman: J. Fish. Res. Bd. Can., 25, 1561-1569 (1969).

7) M. Matsui, T. Watanabe, and N. Ikekawa: Bull. Japan. Soc. Sci. Fish., 39, 367-373 (1973).

8) T. Watanabe and T. TAkeuchi: Bull. Japan. Soc. Sci. Fish., 42, 893-906 (1976).

9) T. Watanabe, F. Takashima, and C. Ogino: 
Bull. Japan. Soc. Sci. Fish., 40, 181-188 (1974).

10) T. TAKeuchr and T. Watanabe: Bull. Japan. Soc. Sci. Fish., 44, 733-738 (1978).

11) M. Nomura: Bull. Japan. Soc. Sci. Fish., 29, 325-335 (1963).

12) H. Menge, E. C. Miller, and C. A. Denton: Poultry Sci., 42, 1291 (1963).

13) H. Menge, E. C. Calvert, and C. A. Denton: J. Nutr., 87, 365-370 (1965).

14) T. C. YU, R. O. SINNHUBER, and J. D. HENDRICKS: 14, 572-575 (1979).

15) J. D. Castell, R. O. Sinnhuber, J. H. Wales, and D. J. LeE: J. Nutr., 102, 77-86 (1972).

16) T. TAKeUcht and T. Watanabe: Bull. Japan. Soc. Sci. Fish., 48, 1745-1752 (1982).

17) T. TAKeUchi and T. WatANABE: Bull. Japan.
Soc. Sci. Fish., 48, 1307-1316 (1981).

18) T. Takeuchi, T. Watanabe, and C. Ogino: Bull. Japan. Soc. Sci. Fish., 44, 667-681 (1978).

19) T. Takeuchi, T. Watanabe, and C. OgnNo: Bull. Japan. Soc. Sci. Fish., 44, 683-688 (1978).

20) T. TAKeUCHI and T. WATANABE: Bull. Japan. Soc. Sci. Fish., 42, 907-919 (1976).

21) R. LASKER and G. H. THEILACKER: J. Lipid Res., 3, 60-64 (1962).

22) K. ANDo: J. Tokyo Univ. Fish., 54, 61-98 (1968).

23) Y. Shimma, R. Suzuki, M. Yamaguchi, and T. Aктуама: Bull. Freshwater Fish. Res. Lab., 27, 35-48 (1977).

24) T. Watanabe, T. Takeuchi, and Y. Shimma: Bull. Freshwater Fish. Res. Lab., 28, 37-46 (1978). 